\title{
METHODS FOR THE ASSESSMENT OF THE EFFECTS OF DRUGS ON RENAL BLOOD FLOW
}

\author{
R.M. PEARSON \\ Medical Unit, The Royal Free Hospital, \\ Pond Street, Hampstead, London NW3 2QG
}

\section{Renal blood flow}

In man, total renal blood flow (RBF) is about 1.2 $1 / \mathrm{min}$, some $25 \%$ of the cardiac output and therefore of considerable circulatory importance. Recent trends in physiology have focused interest on the relationship between RBF and the control of tubular reabsorption. With the introduction of powerful pharmacological agents which affect the resistance to renal blood flow, there has been increasing interest in accurate methods for its measurement.

The average blood flow in terms of flow/g tissue is greater in the kidney at 3-5 ml min-1 $\mathrm{g}^{-1}$ than in most other organs. This average reflects mainly cortical flow since the perfusion of the inner medulla and papilla is only one tenth of this value. Even papillary flow however is not much less than the average perfusion of the brain so that papillary flow is 'low' only in comparison with the renal cortex. The kidney has remarkably constant blood flow in comparison with many other organs. An appreciable increase in RBF may occur acutely in fever and over several days in response to nephrectomy. Under more physiological conditions, however, RBF rarely rises above the normal basal levels and is seldom reduced by more than $50 \%$. It was demonstrated early in the history of measurement of renal blood flow (Smith, 1940) that apprehension could reduce renal blood flow significantly.

Anatomical studies have distinguished two groups of nephrons with different physiological properties and blood supplies. Some $85 \%$ of nephrons are of cortical type with their glomeruli in the outer twothirds of the cortex. The remainder are of juxtaglomerular type whose glomeruli are adjacent to the junction of the cortex and medulla. These two groups of nephrons have different physiological properties as a result of different arrangements of their blood supplies and their tubules. Each interlobular artery first supplies branches to the glomeruli of the juxtaglomerular group and then to the glomeruli of the cortical nephrons.

The afferent arteriole which supplies a glomerulus of the cortical nephrons has a muscular wall by which the resistance to blood flow is regulated. Its tone varies with changes in perfusion pressure which is mediated by the juxtaglomerular apparatus of which the afferent arteriole is a part. This control system gives the cortical group of nephrons their property of autoregulation - the ability to maintain a constant plasma flow to a glomerulus in the face of changes in perfusion pressure between wide limits (70-170 $\mathrm{mmHg}$ systemic arterial pressure). The afferent arteriole of a glomerulus of the juxtamedullary group is less sensitive to vasoconstrictor stimuli and the nephrons of this group do not exhibit autoregulation.

Interest in the intrarenal distribution and redistribution of blood flow has been stimulated by various demonstrated or alleged functional implications including: (1) juxtaglomerular diversion with cortical hypoxia and tubular damage (2) medullary flow as a determinant of medullary osmolarity and renal concentrating capacity and (3) distribution of blood flow as a determinant of sodium excretion.

Glomerular filtration is also maintained at a constant level in the face of changes in renal perfusion pressure and this stresses the interdependence of renal blood flow and glomerular filtration rate.

Most methods for measuring renal blood flow in man are necessarily indirect and require a finite length of observation. These limitations have often been ignored as have changes in renal blood flow which are transient or due to variations caused by discomfort to the subject.

\section{Clearance and extraction methods}

Urine is apparently easily collected and early attempts to measure renal blood flow were based on the clearance of substances extracted almost completely by the kidney. A substance can be envisaged whose uptake by the kidney from renal arterial plasma by glomerular filtration and tubular secretion, is complete so that none appears in renal venous plasma. This imaginary substance would have an extraction efficiency, $E$, of $100 \%$. The amount that appears in the urine per minute $(U \times V / t)$ equals the amount supplied in the renal arterial plasma.

$$
\text { so } \mathrm{U} \times \mathrm{V} / \mathrm{t}=\mathrm{C} \times \mathrm{P}
$$


where $C$ is the clearance of the hypothetical substance, $P$ is the plasma concentration of the substance in $\mathrm{mg} / 100 \mathrm{ml}$. Since

$$
\mathrm{C}=\mathrm{E} \times \mathrm{RPF}
$$

where $R P F$ is the renal plasma flow, $C$ is the RPF where the substance is completely extracted, i.e. $\mathrm{E}$ is $100 \%$

The first attempts to measure renal plasma flow used hippuran and phenol red (Chassis, Ranges, Goldring \& Smith, 1938). The extraction efficiency of these compounds was between 80 and $95 \%$ so that here $\mathrm{RPF}=\mathrm{C} / 0.85$ when $\mathrm{E}=85 \%$. Renal blood flow is derived by dividing renal plasma flow by the haematocrit. The product of $E \times R P F$ is known as the effective renal plasma flow (ERPF).

It was later found that $\rho$-amino hippuran acid (PAH) was easier to measure than hippuran (Smith, Finkelstein, Aliminosa, Cranford \& Graber, 1945) and this technique has been in use for many years. There are however some unwarranted assumptions in the derivation of the value for ERPF which was equated with PAH clearance since as a measure of renal function it was defined in terms of the function it was designed to measure. It is assumed that plasma perfuses tubules that are uniformly efficient in extracting PAH but it has since been shown in various species that the extraction efficiency of the nephrons of the juxtamedullary group is substantially lower that that of the cortical group.

Extraction of PAH and hippuran depends on a specific carrier whose activity is theoretically saturable at high plasma concentrations of substrate. However, it has been found that clearance is not significantly depressed with the techniques usually employed.

\section{Practical aspects of PAH clearance}

In practice PAH is given with a loading dose followed by a continuous intravenous infusion. A steady state is achieved $30 \mathrm{~min}-2 \mathrm{~h}$ after the start of the collection.

To establish an appropriate plasma concentration of PAH an injection of $8 \mathrm{mg} / \mathrm{kg}$ should be given. The priming injection should be preceded or immediately followed by the establishment of a constant intravenous infusion of PAH at a rate calculated to approximate to equal or preferably slightly exceed the calculated rate of renal clearance (Smith, 1956). This calculation is more critical than the priming dose.

Certain precautions must be observed. The solution of PAH must be made up in saline, never distilled water. The priming dose must be given slowly to avoid vasomotor and other autonomic disturbances. Large doses of PAH are dangerous to subjects with poor renal function and the PAH method is contraindicated in anuric and oliguric patients.

An alternative technique to achieve steady state plasma levels without an intravenous infusion has been described (James, 1968) in which a volume of PAH solution is injected into the soft tissues of the axilla.

In all renal clearance studies, the most elementary consideration is the accurate collection of carefully timed urine samples. This can rarely be achieved by voluntary emptying of the bladder even in healthy volunteers and precise observations require that urine is collected via an indwelling catheter. Urine collection periods should not be of less than 20 min duration. If a catheter is inserted the bladder can be emptied more completely by gentle suprapubic pressure and the last urine removed by instillation of a measured volume of sterile water or saline if urine flow is low $(10 \mathrm{ml} / \mathrm{min})$. Stoppered tubes should be used to collect $30 \mathrm{ml}$ aliquots from the measured urine collections. To facilitate accurate urine collection a diuresis can be induced by the oral administration of $200-400 \mathrm{ml}$ water every $20 \mathrm{~min}$ according to the urine flow.

Where the plasma concentration of a solute $(\mathrm{P})$ is changing from moment to moment, the true average concentration over any interval of time where $\mathrm{dP} / \mathrm{dt}$ is exponential is given by:

$$
P_{1}-P_{2} / 2.3 \log P_{1} / P_{2}
$$

For most purposes however, a graphical interpolation is sufficient. Successive plasma concentrations $\left(\mathrm{P}_{1}, \mathrm{P}_{2}, \mathrm{P}_{3}\right.$ etc) are plotted on semi-logarithmic graph paper against elapsed time, taking zero time either as the time at which the priming injection is administered or as the time at which the bladder is emptied and the collection of urine is begun. The exact value of $P$ appropriate to each successive urine collection period is determined by interpolating to the value $6 \mathrm{~min}$ before the mid-time of the urine collection period. This correction for 'delay time' is to allow for the time elapsing between the collection of a peripheral sample of venous blood and the arrival in the bladder of urine formed from that blood. This correction is imprecise and varies with the rate of urine flow and the size of the kidneys. After an instantaneous change in P, $30 \mathrm{~min}$ are required for the urine to come into equilibrium with the arterial blood largely because of dead space in the tubules, collecting ducts and the pelvis.

The determination of blank values is of importance in the estimation of PAH in the plasma (Smith et al., 1945). Recovery of PAH in filtrate is more complete if a dilute solution of cadmium sulphate is used as a protein precipitant. Assay of PAH is time consuming although an autoanalyser method has been described (Looye, 1970). Simultaneous intravenous infusion of glucose or administration of sulphonamides or procainamide interfere with analysis of PAH. Some local anaesthetics also interfere with estimation of PAH and these must be avoided for the insertion of intravenous cannula and urethral catheters. To ease 
the passage of the urethral catheter $\mathrm{KY}$ jelly is appropriate and does not interfere with analyses.

PAH is conjugated in the para position in man. The presence of this conjugated metabolite does not interfere with the measurement of PAH for estimation of ERPF. In any case after intravenous infusion the amount of conjugated material is very small.

Since the measurement of ERPF by PAH clearance requires urine collections of at least $20 \mathrm{~min}$, the value for PAH represents a mean value of the ERPF during that time. It conceals fluctuations in the actual plasma flow rate that might occur during that time to give a false impression of the stability of renal plasma flow. Other techniques for measuring RPF demonstrate its variability, its sensitiveness to anxiety, emotion, noise, upright posture and to reflexes initiated by stimuli to the cervix, bladder and femoral artery. All of these tend to reduce RPF.

Despite these limitations, PAH infusion is still widely used to measure the effects of drugs such as dopamine (Orme, Breckenridge \& Dollery, 1973), bupicomide (Chrysant, Adamopoulos, Tsuchiya \& Frolich, 1976) and prazosin (Koshy, Mickley, Bourgoignie \& Blaufox, 1977).

\section{Radiolabelled hippuran}

Hippuran was originally introduced as a contrast medium for excretion urography. It is chemically similar to PAH being iodinated in the ortho position to give sodium ortho-iodohippurate. It is neither metabolized nor synthesized in the body and is excreted entirely in the urine of subjects with normal renal function. The clearance of hippuran in man is very similar to that of PAH (Smith et al., 1945).

Radio-iodinated [ $\left.{ }^{131} \mathrm{I}\right]$-hippuran was developed to eliminate cumbersome chemical determinations in the estimation of ERPF and to replace them by simple isotopic counting methods (Burbank, Tauxe, Maher \& Hunt, 1961; Schwartz \& Madeloff, 1961). The values obtained for ERPF using radiohippuran are slightly lower than those obtained from simultaneous estimations using PAH. These differences may be related to differences in protein binding, since only the unbound fraction is cleared (Maher \& Tauxe, 1969). Differences in molar concentrations (Maher, Tauxe, Strong \& Elveback, 1970) or free iodide may also be significant. Certainly when the free iodide content rises above $2 \%$ the differences between PAH and hippuran clearances became significant. The importance of checking samples of [ $\left.{ }^{131} \mathrm{I}\right]$-hippuran for free iodide and contaminating iodobenzoic acid has been emphasized (Varga, Keleman \& Kovach, 1968). Radiohippuran clearances have been used to study the effects of drugs such as indomethacin (Donker, Arisz, Bretjens van der Hem \& Hollemans, 1976) and alprenolol (Pedersen, 1975) on renal blood flow in man.

Most of the radioactivity administered is retained in the thyroid due to free iodide unless thyroid uptake is blocked by prior administration of unlabelled potassium iodide. The whole body dose of radiation from [ $\left.{ }^{131} \mathrm{I}\right]$-hippuran is about $2 \mathrm{~m} \mathrm{Rem} / 10 \mu \mathrm{Ci}$ (Henk, Cottrall \& Taylor, 1967). Radiation dosage using these techniques is less than $5 \%$ of that from an IVP.

To overcome the inconvenience of delivering a continuous infusion, techniques were developed for the measurement of ERPF using a single injection of [ $\left.{ }^{131} \mathrm{I}\right]$-hippuran (Gott, Prichard, Young \& MacIntyre, 1962; Wagoner, Tauxe, Maher \& Hunt, 1964). From a series of measurements of plasma radioactivity and hence concentration of $\left.{ }^{131} \mathrm{I}\right]$-hippuran after rapid intravenous injection it was possible to derive a value for ERPF assuming a single compartment. The volume of distribution $\left(V_{d}\right)$ was obtained by extrapolating the concentration/time curve back to $t_{0}$. The clearance $(E R P F)=V_{d} / \lambda$ where

$$
\lambda=0.693 / T_{1} \text {. }
$$

The values thus obtained correlated well with those from simultaneous estimations by PAH infusion. Subsequently it was shown (Blaufox \& Merrill, 1966) that comparable values for ERPF could be obtained after bolus intravenous injection of [ $\left.{ }^{131} \mathrm{I}\right]$-hippuran and collection of only two blood samples at 20 and $30 \mathrm{~min}$ after the intravenous injection.

A pharmacokinetic model of the clearance of substances from the kidney suggested that an open two-compartment mammillary system was more appropriate (Sapirstein, Vidt, Mandel \& Hanhsek, 1955). From a series of observations of plasma concentrations of hippuran after rapid intravenous injection, it is possible to estimate quantities interpretable as concentrations within volumes of distribution in the body, intercompartmental clearances and ERPF. The radioactivity is plotted against time on semi-log paper.

A close fit of the results was obtained by using the equation

$$
\mathrm{C}_{\mathrm{t}}=A \mathrm{c}^{-\mathrm{at}}+B \mathrm{c}^{-\mathrm{bt}}
$$

where

$$
\mathrm{C}_{\mathrm{t}}=\text { counts } \mathrm{s}^{-1} \mathrm{ml}^{-1} \text {. }
$$

Terminal segments of the biexponential curves were extrapolated linearly to the ordinate and the intercept value (A) obtained. The second curve (after log transformation as a straight line) is obtained by subtraction of the terminal curve and its intercept (B) found. Fractional disappearance rates $\lambda a$ and $\lambda b$ are determined from the half-times ta and tb of the lines by the equations:

$$
\mathrm{e}^{-\lambda \mathrm{ata}}=\frac{1}{2}, \lambda \mathrm{a}=\log 2 / \mathrm{ta}, \lambda \mathrm{b}=\log 2 / \mathrm{tb} .
$$

An aliquot of the injected dose is also counted and the total injected counts/second calculated and designated I. Plasma concentration at any time $t$ is $\mathbf{C t}$ 


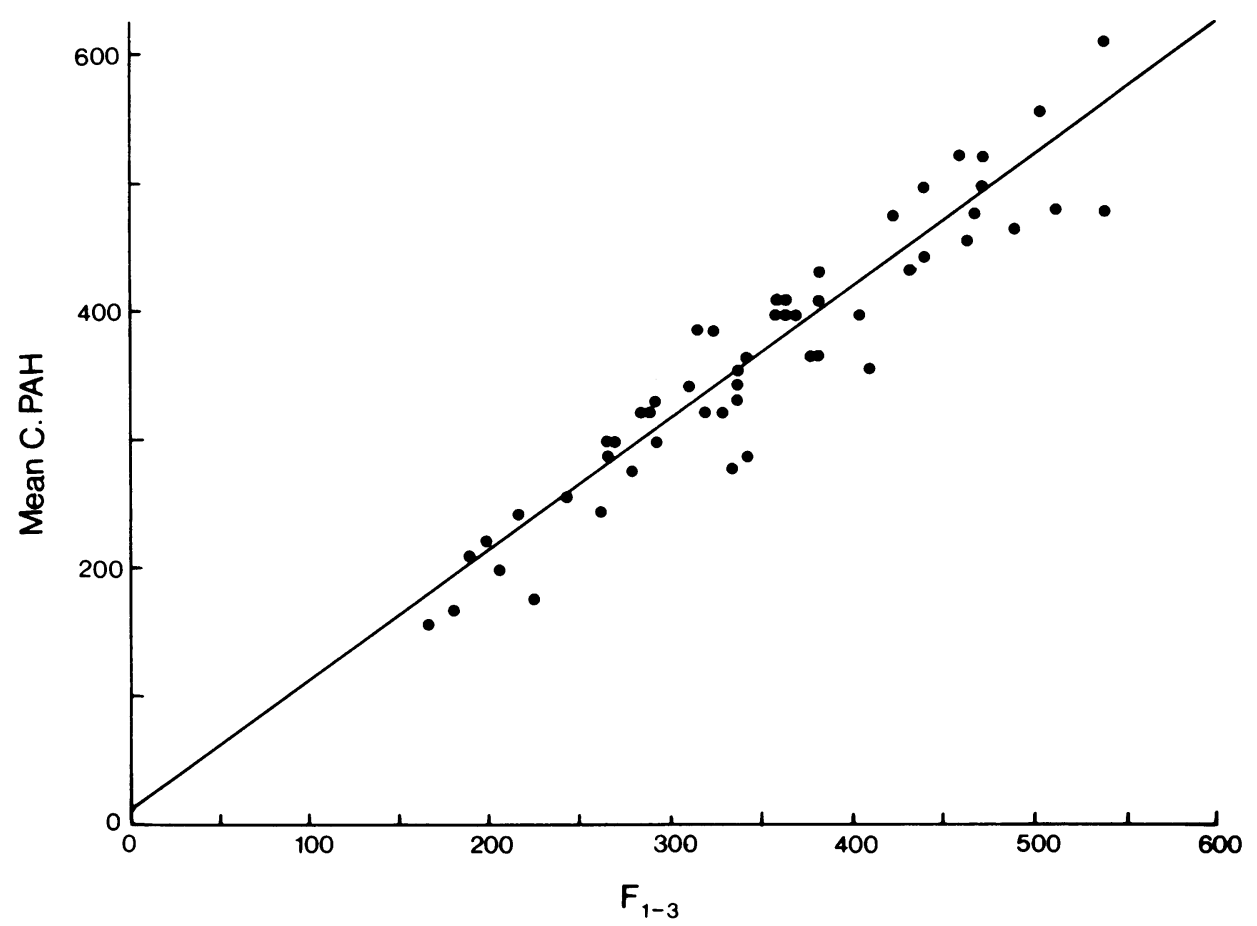

Figure 1 Correlation of mean clearance of $p$-aminohippuran acid (CPAH) values and simultaneously performed estimates of effective renal plasma flow (ERPF) by compartment analysis of plasma disappearance curves $\left(F_{1-3}\right)$ following a single injection of $\left[{ }^{131} 1\right]$-hippuran. $r=0.95$ (from Tauxe, Maher \& Taylor 1971) reproduced with permission.

(counts $\mathrm{s}^{-1} \mathrm{ml}^{-1}$ ). The theoretical volume of distribution that would contain the $\left[{ }^{131} \mathrm{I}\right]$-hippuran at the concentration found in the plasma at any given time is then $\mathrm{I} / \mathrm{Ct} \mathrm{ml}$ or $\mathrm{I} / \mathrm{Ct} 10^{-3} \mathrm{l}$.

Applying this notation to the two-compartment model and where:

$V_{1}$ is the volume into which the injection is made

$\mathrm{V}_{2}$ is the interchangeable volume

$F_{1-2}$ and $F_{2-1}$ are the intercompartmental flow rates

$\mathrm{V}_{3}$ is the end volume (kidney and beyond)

$F_{1-3}$ is the flow rate from $V_{1}$ to $V_{3}$

Fractional intercompartmental flow rate constants are designated $\mathrm{K}_{1-2}, \mathrm{~K}_{2-1}$ and $\mathrm{K}_{1-3}$.

These rate constants can be calculated by dividing the flow rates by the respective volumes or from the equation:

$$
F_{1-3}=I \int_{0}^{\infty} C t^{\prime} \cdot d t^{\prime}=\frac{I a b}{A \lambda b+B \lambda a} .
$$

The considerable advantage of techniques not involving urine collection is of course their suitability for use in anuric or oliguric subjects. Plasma and not whole blood should be counted since hippuran which is sequestered in red blood cells is not available for clearance. The plasma sampling technique has been further refined (Tauxe, Maher \& Taylor, 1971) so that a single blood sample can be used to estimate ERPF. At low values for ERPF (below $200 \mathrm{ml} / \mathrm{min}$ ) samples at 2 and $4 \mathrm{~h}$ after injection may be preferable (Morgan, Birks, Sivyer \& Ghose, 1977). It correlates well with the PAH method (Figure 1).

External counting methods have been used to measure clearance of $\left[\left[^{125}\right]\right.$-hippuran (Ram, Evans \& Chisholm, 1968). The evidence from animal studies (Prichard, Eckstein, MacIntyre \& Dabaj, 1960) suggests a good correlation between the results from [131I]-hippuran clearance and direct measurements of flow. The introduction of Computer Assisted Blood Background Subtraction to analysis of the [131 I]hippuran venogram obtained by external counting can be used to accurately proportionate the contribution of each kidney to total ERPF (Britton \& Brown, 1971).

Differentiation of the outer glomerular flow from that of the juxta medullary glomeruli is of especial interest in the study of the responses of the intrarenal circulation to drugs. The isotopic venogram has been 
used to distinguish blood flow through the two populations of nephrons. The transit times of [ $\left.{ }^{131} \mathrm{I}\right]$ hippuran can be derived from the renogram curves. Deconvolution of the uptake and removal functions of | ${ }^{131}$ I|-hippuran yields a value for transit times (Britton, Brown, Cruz, Chang, Rolphs \& Myers, 1976).

From this it was demonstrated that the distribution of tracer transit time through the kidney was bimodal. Normally the more rapid transit mode has a peak time of about $2.5 \mathrm{~min}$ and probably represents flow of tracer through the tubules of the outer cortical nephrons. The slower transit mode has a peak at about $5 \mathrm{~min}$ and is thought to correspond to transit of | ${ }^{131} \mathrm{I} \mid$-hippuran through the longer juxtaglomerular nephrons. Since the secretion of tracer into a nephron is proportional to its plasma flow, the area for each mode of the frequency/distribution curve for transit times will be proportional to plasma flow in each group of nephrons. Studies in animals (Wilkinson, Bernardi, Pearce, Britton, Brown, Poston, Clarke, Jenner \& Williams, 1978) confirm this interpretation by comparing the results of transit venography with that from microsphere distribution.

\section{Indicator dilution}

Indocyanine green (IG) which is strongly bound to plasma albumin has been used to measure RBF by the indicator dilution method (Reubi, Gorsweiler \& Gertler, 1966). This technique involves catheterization of the renal artery and renal vein. The dye is injected into the renal artery and measured in the renal vein by a continuous recording densitometer. A correction is employed for errors due to recirculation of dye. Attempts have been made to measure renal cortical and medullary blood flow separately but no convincing results have been presented. Recently the results of RBF from the IG method have been compared with those from a technique using ${ }^{99} \mathrm{~m}$ Tclabelled erythrocytes (Reubi, Vorburger, Pfeiffer \& Golder, 1977). It was found that IG slightly overestimates RBF in patients with normal renal function probably due to the incomplete recovery of IG by trapping of the dye within the kidney. Correlation between the results from the IG technique and from PAH infusion are moderately good.

[131I]-hippuran has also been used as an indicator to measure RBF by constant infusion into the renal artery and sampling from the renal vein (Schalekamp, Birkenhager, Zaal \& Kolsters, 1977). The mean extraction ratio of hippuran was $74 \%$ which is rather lower than usually assumed.

An isotopic indicator dilution method (Shillingford, Bruce \& Gabe, 1962) has been adapted to measured renal blood flow within the renal vein (Dollery, Gordon \& Pentecost, 1965). In this technique, the renal vein is catheterized and [ $\left.{ }^{125} \mathrm{I}\right]$-albumin is infused through and end-hole and sampled from the side hole of a double-lumen catheter. There is a good correlation between this technique and the PAH method (Breckenridge, Orme \& Dollery, 1971).

\section{Gas washout methods}

The measurement of regional blood flow with inactive, highly diffusible indicators was first applied to renal blood flow using nitrous oxide (Conn, Anderson \& Arena, 1953; Crossley, Brown, Huston, Emanuel, Tuchman, Eastillo \& Rowe, 1956). This technique required inhalation of nitrous oxide and catheterization of the femoral artery and renal vein. Soon afterwards radioactive krypton was introduced (Brun, Crone, Davidson, Fabricius, Hansen, Lassen \& Munck, 1955). This had the distinct advantage that it was easier to estimate in blood samples although ${ }^{85}$ krypton, a $\beta$-emitter, cannot easily be counted externally. ${ }^{85}$ Krypton is inhaled in air for $10 \mathrm{~min}$ after which time saturation of the kidney was assumed to have occurred. Samples were taken from the femoral artery and renal vein before and after saturation.

The introduction of ${ }^{131}$ xenon, a $\gamma$-emitter, as an indicator allowed external scintillation counting of the washout curve (Ladefoged, 1966). Injection of ${ }^{133}$ xenon into the renal artery is conveniently performed in conjunction with arteriography in the investigation of patients for unilateral renal disease or in potential live renal donors.

The partition coefficient of xenon is only $65 \%$ of that of krypton which allows a faster washout curve and more rapid recognition of the terminal component. Pulse height discrimination is more sensitive if xenon rather than krypton is employed because of the narrower energy spectrum of xenon. This allows a more narrowly collimated 'window' and reduced background interference especially from the lungs.

Each curve tracing takes about $40 \mathrm{~min}$. The error between successive observations in the 'steady state' is in the order of $2 \%$.

After injection of the bolus of ${ }^{133}$ xenon dissolved in $1 \mathrm{ml}$ saline, the renal catheter is flushed with isotonic saline or withdrawn from the renal artery and immediately cleared of radioactivity by withdrawal of $10 \mathrm{ml}$ of blood through it. Gas solution must be kept in the catheter for the minimum of time bacause of gas uptake by certain radio-opaque catheters (Peters \& Eichling, 1972). Plastic syringes and tubes should be avoided in the sampling of blood for analysis of xenon because of the solubility of xenon in many plastics. Gas syringes with tight fitting metal Luer locks are appropriate. The effects of bolus injection into the renal artery have been critically assessed (Mowat, Lupu \& Maxwell, 1972) after the observation in the dog that following bolus injections, renal blood flow as recorded with an electromagnetic flow meter fell 
rendering the estimation of renal blood flow by the ${ }^{133}$ xenon method inaccurate. These data emphasize the importance of keeping the volume of the arterial injection as low as possible in order to prevent unpredictable decreases in renal blood flow. Catheter diameter affects renal blood flow only when it approaches the internal diameter of the renal artery (Bjorno \& Pettersson, 1977; Hellsten \& Pettersson 1977).

It has been pointed out (Britton, Brown \& Bluhm, 1971) that any curve whose shape is like the xenon washout curve can be resolved into three or more exponential components. This type of analysis implies a compartmental model of the system under study. The basic assumption of such a compartmental model is that the rate of mixing in each compartment is very rapid compared with the rate of exchange between compartments. The compartments are usually considered to represent the outer renal cortex ${ }^{(\mathrm{I})}$, the juxtaglomerular region and outer medulla ${ }^{(I I)}$, the inner medulla (III) and renal fat (IV). Since a kidney is in reality composed of systems of tubes (nephrons and blood vessels of various dimensions) there is little chance of rapid mixing of xenon throughout, for example, the outer cortex. Nor is it obvious that the rate of mixing in the outer cortex is faster than the rate of exchange between outer and inner cortex. It is also unlikely that the specific activity of tracer is uniform throughout each compartment. Thus the failure of a compartmental model of regions of the kidney to meet the basic requirements of compartmental analysis is the basis of the theoretical objection to the use of the ${ }^{133}$ xenon washout technique to measure the intrarenal distribution of renal blood flow.

Despite these theoretical considerations it has been argued that the components of the xenon washout curve can in practice be related to the intra-renal distribution of blood flow. There are, however, further objections to justifying the technique even on empirical grounds. The interlobular artery supplies branches to glomeruli in the juxtamedullary region before supplying the glomeruli of the outer cortex, yet auto radiographic studies in animals using ${ }^{85}$ krypton imply that the outer cortex is perfused first and then the juxtaglomerular region (Thorburn, Kopald, Herd, Hollenberg, O'Marchoe \& Barger, 1963; Hollenberg, Mangel \& Fung, 1976).

The persistence of ${ }^{133}$ xenon in the medulla relative to the cortex may not result soley from an effect due to blood flow. Alternatively it could occur from the transfer of ${ }^{133}$ xenon to the medulla from cortical nephrons via loops of Henle and collecting ducts. The higher lipid content of the medulla relative to the cortex and the high solubility of xenon in lipid may also contribute. The accuracy of measurement of a third component is likely to be small (Glass \& de Garetta, 1971). Measurements derived from the second component vary inversely with those derived from the first component in results from normal kidneys and measurements from the first component correlate with cortical flow as assessed by a technique using microspheres (Slotkoff, Logan, Jose, D'Avella \& Eisner, 1971).

The theoretical background of the gas washout method is based on the work of Kety (1951). It is based on the assumption that the diffusibility of the inert gases is sufficiently high to maintain equilibrium under all physiological conditions between the tissue and the blood leaving the tissue.

If the Fick principle is applied, then the following equations can be derived for uptake and washout of inert gas from a tissue.

$$
\mathrm{dQ} / \mathrm{dt}=\mathrm{f}(\mathrm{Ca}-\mathrm{Cv})
$$

where $d Q / d t$ is the amount of tracer removed per unit time, $\mathrm{f}$ is the blood flow in $\mathrm{ml} / \mathrm{min}, \mathrm{Ca}$ is the arterial concentration of gas, $\mathrm{Cv}$ is the venous concentration of gas.

The total amount of gas in the tissue $(\mathrm{Q})$ is

$$
\mathrm{Q}=\mathrm{C}_{\mathrm{t}} \mathrm{W}
$$

where $C_{t}$ is the tissue concentration of gas, $W$ is the weight of tissue, $=$ Volume $\times$ specific gravity. Note the specific gravity of kidney is near unity.

Blood leaving the kidney is virtually cleared of gas in a single passage through the lung. Therefore the arterial concentration of gas immediately after injection is zero. Also the venous concentration of gas is related to the tissue concentration:

$$
\mathrm{p}=\mathrm{Ct} / \mathrm{Cv}
$$

where $p$ is the partition coefficient of gas between tissue and blood. The original equation can be rewritten as

$$
\begin{gathered}
\mathrm{W} \mathrm{dCt} / \mathrm{dt}=\mathrm{f}(\mathrm{Ct} / \mathrm{p}) \\
\mathrm{d} \mathrm{Ct} / \mathrm{Ct}=(\mathrm{f} / \mathrm{W})(\mathrm{l} / \mathrm{p}) \mathrm{dt}
\end{gathered}
$$

where $f / W=F=$ flow rate per unit weight

$$
\text { Therefore } \mathrm{dCt} / \mathrm{Ct}=\mathrm{F} / \mathrm{p} d \mathrm{t}
$$

The blood flow rates $F$ calculated from washout curves must be expressed as $\mathrm{ml} \mathrm{min}^{-1} \mathrm{~g}^{-1}$ of tissue. Absolute flow rates per kidney cannot be determined with this method. This disadvantage is perhaps offset by the ability to estimate the degree of ischaemia which can be defined as the reduction of flow rate/g of perfused tissue. If blood is sampled from the renal vein absolute measurements of blood flow can be obtained (Zierler, 1965).

For a uniformly perfused tissue the equation has the general form: $\mathrm{Ct}=\mathrm{Ct}_{\mathrm{o}} \mathrm{e}^{-\mathrm{F} / \mathrm{pt}}$.

The total amount of tracer $Q$ in an organ is expressed by $Q=Q_{0} e^{-} F / p t$

and for an organ with several compartments by:

$$
\mathrm{Q}=\mathrm{Q}_{01} \mathrm{e}^{-k_{1} \mathrm{t}}+\mathrm{Q}_{02} \mathrm{e}^{-\mathrm{k}_{2} \mathrm{t}}+\ldots
$$




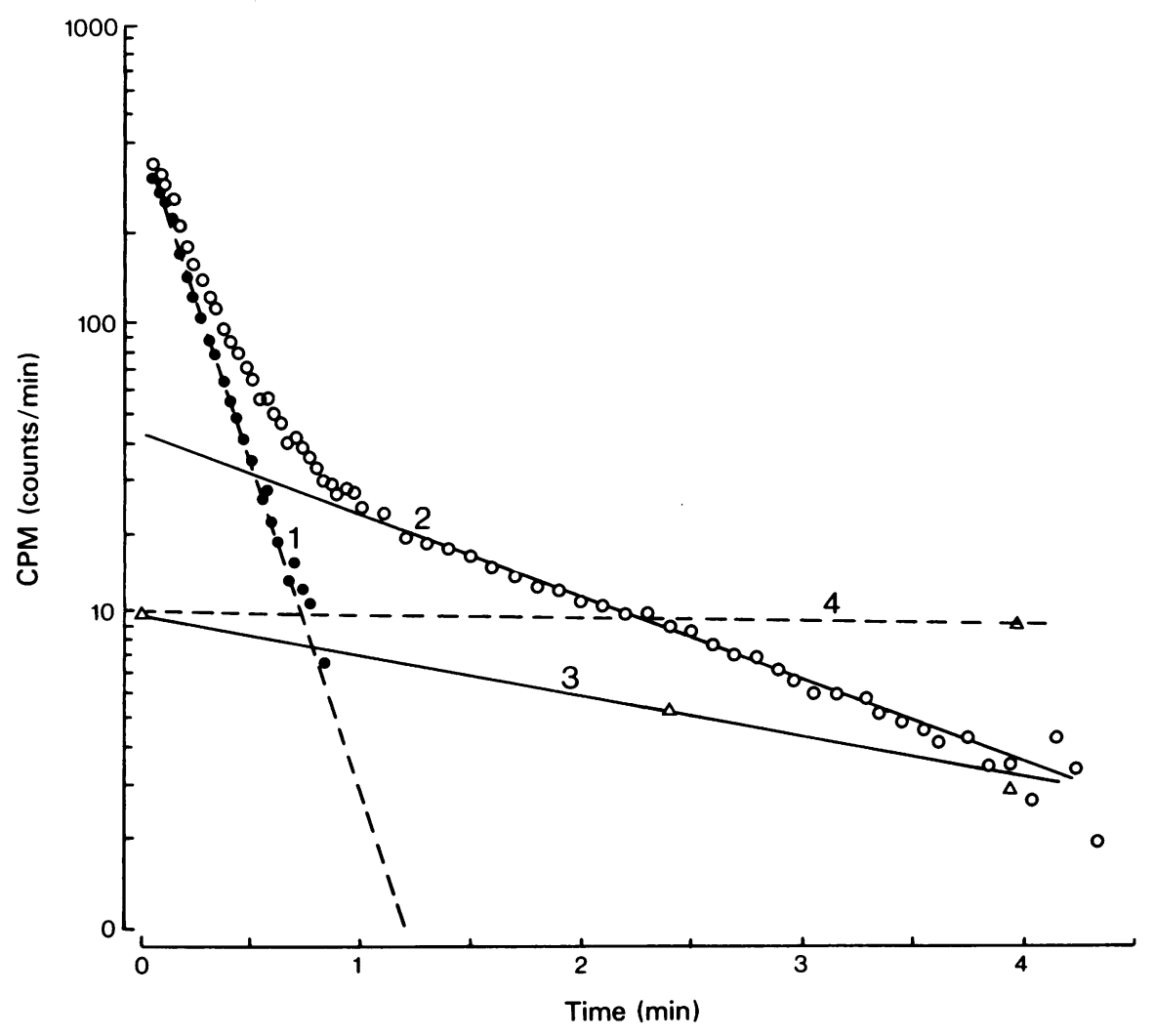

Figure 2 Compartmental analysis of xenon disapppearance from the kidney of a normal subject on a high salt $(100 \mathrm{mEq})$ diet. The curve has been analysed as the sum of four exponential functions. $1 \mathrm{C}_{1} \%=83.6$, $T_{\frac{1}{2}}=7.75 \mathrm{~s} ; 2 \mathrm{C}_{\|} \quad \%=10.7, T_{\frac{1}{2}}=68 \mathrm{~s} ; 3 \mathrm{C}_{\| \mid} \%=2.8 T_{\frac{1}{2}}=144 \mathrm{~s} ; 4 \mathrm{C}_{\mathrm{IV}} \quad \%=2.7, T_{\frac{1}{2}}=2400 \mathrm{~s}$. Only the first 4 min are shown (from Hollenberg et al., 1970) reproduced by permission.

where $k=F / p=$ slope of any of the compartments of the washout curve plotted on semilogarithmic paper. The slope is expressed as $\mathrm{k}=0.693 / T_{\frac{1}{2}}$, and hence the flow rate in each compartment is $F=k p$.

The mean renal blood flow (MRBF) may be calculated either from the initial slope of the washout curve (Hollenberg, Epstein, Guttman, Conroy, Basch \& Merrill, 1968) or by the integration method (Zierler, 1965; Ladefoged, 1966) from $M R B F=($ Maximum height/area under curve). $p$.

The multiexponential washout curve plotted on semilogarthmic paper may be analysed graphically by compartmental analysis of the exponential strip method (Thorburn et al., 1963). Four components have been isolated from 35-40 min curves (Rosen, Hollenberg, Daly \& Merrill 1968; Hollenberg et al., 1968) and three components were identified from the 20-30 min curves (Ladefoged, 1966) (Figure 2). However, it was shown (Dell, Siacca, Lieberman, Case \& Cannon, 1973) that there were no significanct differences in the estimation of the flows in each. compartment made from 20 min curves from those made from 40-60 min curves.

The fraction of the total amount of injected gas initially present in each compartment is determined by dividing the intercept of each individual component by the sum of the intercepts of all components at time zero. It reflects the fraction of total renal blood flow perfusing the area represented by the curve component. The fractions will vary according to the manner in which the curve is plotted. For example the distribution of gas in the first compartment will tend to decrease in magnitude if the inflection point of the curve is considered as zero time.

Useful approximations may be made from washout curves recorded over a shorter time. It was shown in man (Hollenberg et al., 1968) that the value at 4.5 and 3 min respectively may be subtracted from the original curve as an approximation of the two slowest components. The result for the first rapid component 
did not differ significantly from that derived from 40 min curves.

Subjectivity in analysis by the exponential strip method may introduce bias which can be obviated by duplicate assessment. For graphical analysis, halftimes $\left(T_{\frac{1}{2}}\right)$ must differ by a factor of 3 to achieve separation. Computer programs have been designed to analyse the data by the technique of maximum likelihood (Hollenberg, Sandor, Conroy, Adams, Solomon, Abrams \& Merrill, 1973) or the weighted least-squares technique (Dell et al., 1973). Neither method is clearly preferable and it may be that the precision of computer analysis exceeds the accuracy and physiological significance of the gas washout method. Attempts have been made to improve the resolution of graphical analysis in order to enhance separation of exponetial functions.

Sodium balance influences the intrarenal distribution of renal blood flow in normal and hypertensive man (Hollenberg, Epstein, Guttman, Conroy, Basch \& Merrill, 1970). Restriction of sodium intake below $(10 \mathrm{mEq} /$ day reduces flow in the 'fastest' compartment whereas an intake of 200 $\mathrm{mEq} /$ day has the opposite effect. Thus the sodium balance of subjects should be considered in interpretation of the results obtained from the xenon washout method. The current status of the xenon washout technique is probably that it can be used to measure MRBF and the cortical fraction of total RBF but not reliably medullary RBF. Xenon washout has been used to examine the effect of noradrenaline (Hollenberg, Solomon, Adams, Abrams \& Merrill, 1972) acetylcholine (Rashuda, Hollenberg, Adams, Solomon, Abrams \& Merrill, 1972) and saralasin (Hollenberg, Williams, Burger, Ishikawa \& Adams,

\section{References}

BJORN, L., \& PETTERSSON, H. (1977). Hydro and haemodynamic effects of catheterisation of vessels mechanical model. Acta radiol. (Stockh.) Diagnostica. 18, 193-209.

BLAUFOX, M.D. \& MERRILL, J.P. (1966). Simplified hippuran clearance. Nephron, 3, 274-281.

BRECKENRIDGE, A., ORME, M. \& DOLLERY, C.T. (1971). Effects of dopamine on renal blood flow in man. Eur. $J$. clin. Pharmac. 3, 131-136.

BRITTON, K.E., BROWN, N.J.G. \& BLUHM, M.M. (1971). Xenon washout. Lancet, ii, 822.

BRITTON, K.E. \& BROWN, N.J.G. (1971). Clinical Renography. London: Lloyd-Luke.

BRITTON, K.E., BROWN, N.J.G., CRUZ, F., CHANG, H.C., ROLPHS, D. \& MYERS, M. (1976). Deconvolution analysis of dynamic curves. In Information Processing in Scintigraphy. Proc. IV Int. Conf. pp 244-260, Ed. Raynaud C. \& Todd Pokropek, A. Orsay, Paris.

BRUN, C., CRONE, C., DAVIDSEN, H.G., FABRICIUS, T., HANSEN, A.T., LASSEN, N.A., \& MUNCK, O. (1955).
1976) on the intrarenal distribution of renal blood flow.

\section{Videodensitometry}

The amount of contrast medium within the kidney can be quantitated by a videodensitometric method at selective angiography (Erikson, Lindgren, Lofroth, Rhun \& Wolgast, 1977). Both the total and regional blood flows within the kidney can be derived when the photographic density is recorded. Analysis of the signal gives a dilution curve which is identical from that derived from a simultaneous isotope dilution record. There was good agreement between the result of total blood flow determinations from videodensitometric and isotope ( ${ }^{133}$ xenon) dilution methods. Two limitations of this method should be noted. The video signal derived from different regions of the kidney was influenced by different values of E-an efficiency factor in the system. Also, the calculation of blood flow depends on the measurement of the volume of distribution of the contrast medium. This volume is influenced by the extracellular volume which is altered in pathological states.

\section{Conclusion}

Recent refinements of the [ $\left.{ }^{131} \mathrm{I}\right]$-hippuran and ${ }^{133}$ xenon methods have placed important technique in the hands of investigators wishing to study the effects of drugs on renal blood flow. Further advances, to allow measurement of renal blood flow by the xenon washout technique by which intra-arterial injection is replaced by xenon inhalation may be expected.
Renal blood flow in anuric human subjects determined by the use of radioactive K85. Proc. Soc. exp. Biol. (N.Y.), 84, 687-690.

BURBANK, M.K., TAUXE, W.N., MAHER, F.T. \& HUNT, J.C. (1961). Evaluation of radioiodinated hippuran for the estimation of renal blood flow. Proc. Mayo Clin., 36, 372-386.

CHASSIS, H., RANGES, H.A., GOLDRING, W. \& SMITH, H.W. (1938), The control of renal blood flow and glomerular filtration in normal man. J. clin. Invest., 17, 683-697.

CHRYSANT, S.G., ADAMOPOULOS, P., TSUCHIYA, M. \& FROLICH, E.D. (1976). Systemic and haemodynamic effects of bupicomide. Am. Heart. J., 92, 335-339.

CONN, H.L., ANDERSON, W. \& ARENA, S. (1953). Gas diffusion technique for measurement of renal blood flow with special reference to the intact anuric subject. J. appl. Physiol., 5, 683-689.

CROSSLEY, A.P., BROWN, S.F., HUSTON, J.H., EMANUEL, D.A., TUCHMAN, H., EASTILlO, C. \& ROWE, G.G. 
(1956) Adaptation of nitrous oxide method to determine renal blood flow and in vivo renal weight in man. J. clin. Invest., 35, 1340-1344.

DELL, R.B., SCIACCA, R., LIEBERMAN, K., CASE, D.B. \& CANNON, S.P. (1973). Weighted least-squares technique for analysis of kinetic data and its application to the study of renal ${ }^{133}$ Xenon washout in dogs and man. Circulation Res., 32, 71-84.

DOLLERY, C.T., GOLDBERG, L.I. \& PENTECOST, B.L. (1965). Effects of intrarenal infusions of tradykinin and acetylcholine on renal blood flow in man. Clin. Sci. mol. Med., 29, 433-441.

DONKER, A.J.M., ARISZ, L., BRENTJENS, J.R.H., van der HEM, H. \& HOLLEMANS, H.J.G. (1976). Effect of indomethecin on kidney function and plasma renin activity in man. Nephron, 17, 288-296.

ERIKSON, U., LINDGREN, P.G., LOFROTH, P.O., RUHN, G. \& WOLGAST, M. (1977). Videodensitometry. Acta radiol. (Stockh.) Diagnostica, 18, 225-234.

GLASS, H. I. \& de GARRETTA, A.C. (1971). Quantitative limitations of exponential curve fitting. Phys. in Med. Biol., 16, 119-130.

GOTT, F.S., PRICHARD, W.H., YOUNG, W.R. \& MACINTYRE, W.S. (1962). Renal blood flow measurement from the disappearance of intravenously injected hippuran. J. nucl. Med., 3, 480-485.

HELLSTEN, S. \& PETTERSSON, H. (1977). Hydro- and haemodynamic effects of catheterisation of vessels. Acta radiol. (Stockh.) Diagnostica. 18, 17-24.

HENK, J.M., COTTRALL, M.F. \& TAYLOR, D.M. (1967). Radiation dosimetry of the ${ }^{131} \mathrm{I}$ hippuran renogram. $\mathrm{Br}$. J. Radiol., 40, 327-334.

HOLLENBERG, N.K., EPSTEIN, M., ROSEN, S.M., BASCH, R.I., OKEN, P.E. \& MERRILL, J.P. (1968). Acute oliguric renal failure in man-evidence for preferential renal cortical ischaemia. Medicine (Baltimore), 47, 455-474.

HOLLENBERG, N.K., EPSTEIN, M., GUTTMAN, R.D., CONROY, M., BASCH, R.I. \& MERRILL, J.P. (1970). Effect of sodium balance on intrarenal distribution of blood flow in normal man. J. appl. Physiol. 28, 312-317.

HOLLENBERG, N.K., MANGEL, R. \& FUNG, H.Y. (1976). Assessment of intrarenal perfusion with radioxenon-a critical review of analytical factors and their implications in man. Seminar Nucl. Med., 6, 193-216.

HOLLENBERG, N.K., SOLOMON, H.S., ADAMS, D.F., ABRAMS, H.L. \& MERRILL, J.P. (1972). Renal vascular responses to angiotensism and norepinephrine in normal man. Circulation Res., 31, 750-757.

HOLLENBERG, N.K., SANDOR, T., CONROY, M., ADAMS, D.F., SOLOMON, H.S., ABRAMS, H.L. \& MERRILL, J.P. (1973). Xenon transit through the oliguric kidney. Analysis by maximum likelihood. Kidney Int., 3, $177-185$.

HOLLENBERG, N.K., WILLIAMS, G.H., BERGER, B., ISHIKAWA, I. \& ADAMS, D.F. (1976). Blockade and stimulation of renal adrenal and vascular angiotension II receptors with 1-Sar, 8-Ala, Angiotensin II in normal man. J. clin. Invest., 57, 39-46.

JAMES, I.M. (1968). Haemodynamic and associated metabolic changes following acute cerebrovascular catastrophes, p. 84. Ph.D. Thesis. Cambridge.

KETY, S. (1951). Theory and applications of the exchange of inert gases at the lungs and tissues. Pharmac. Rev., 3, $1-41$.

KOSHY, M.C., MICKLEY, D., BOURGOIGNIE, J. \&
BLAUFOX, M.D. (1977). Physiologic evaluation of a new antihypertensive agent: Prazosin hydrochloride. Circulation, 55, 533-537.

LADEFOGED, J. (1966). Measurements of renal blood flow in man with the ${ }^{133}$ Xenon washout technique. Scand. $J$. clin. lab. Invest., 18, 299-315.

LOOYE, A. (1970). Automated simultaneous determination of $\mathrm{p}$ acetylaminohippurate and inulin in serum. Clin. Chem. 16, 753-735.

MAHER, F.T. \& TAUXE, W.N. (1969). Renal clearance in man of pharmaceuticals containing radioactive iodine. Influence of protein binding. J. Am. med. Ass., 207, 97-104.

MAHER, F.T., TAUXE, W.N., STRONG, C.G. \& ELVEBACK, L.R. (1970). Renal clearance in man of pharmaceuticals containing radioactive iodine. Influence of added carrier iodopyracet and o-iodo-hippurate. Proc. Mayo Clin., 45, $700-711$.

MORGAN, W.D., BIRKS, J.L., SIVYER, A. \& GHOSE, A.R. (1977). Efficient technique for simultaneous estimation of GFR and ERPF. Involving a single injection and two blood samples. Int. J. Nucl. Med. Biol., 4, 79-83.

MOWAT, P., LUPU, A.N. \& MAXWELL, M.H. (1972). Limitations of the ${ }^{133}$ Xenon washout technique in the estimation of renal blood flow. Am. J. Physiol., 223, 682-688.

ORME, M. L'E., BRECKENRIDGE, A.M. \& DOLLERY, C.T. (1973). Effects of long term administration of dopamine on renal function in hypertensive subjects. Eur. J. clin. Pharmac., 6, 155-155.

PEDERSEN, E.B. (1975). Glomerular filtration rate and renal plasma flow in patients with essential hypertension before and after treatment with Alprenolol. Acta med. Scand., 198, 365-371.

PETERS, P.E. \& EICHLING, J.O. (1972). ${ }^{133}$ Xenon uptake by radioopaque catheters. Radiology, 102, 202-204.

PRICHARD, W.H., ECKSTEIN, R.W., MACINTYRE, W.J. \& DABAJ, E. (1965). Correlation of renal blood flow determined by a single injection of hippuran ${ }^{131} \mathrm{I}$ with direct measurements of flow. Am. Heart. J., 70, 789-796.

RAM, M.D., EVANS, K. \& CHISHOLM, G.D. (1968). Single injection method for measurement of ERPF. Br.J. Urol., 40, 425-428.

RASHUDA, A., HOLLENBERG, N.K., ADAMS, D.F., SOLOMON, H.S., ABRAMS, H.L. \& MERRILL, J.P. (1977). Effect of acetylcholine on renal vasculature in normal man. J. appl. Physiol., 32, 669-674.

REUBI, F.C., GOSSWEILER, N. \& GERTLER, R. (1966). Renal circulation in man studied by the dye dilution method. Circulation, 32, 426-442.

REUBI, F.C., VORBERGER, C., PFEIFFER, G. \& GOLDER, S. (1977). Comparison of renal blood flow and transit tissues measure by means of ${ }^{99} \mathrm{Tc}$-labelled erythrocytes and Indocyanine green in humans with normal and diseased kidneys. Clin. Sci. mol. Med., 51, 151-159.

ROSEN, S.M., HOLLENBERG, N.K., DEALY, J.B., MERRILL, J.P. (1968). Measurement of the distribution of blood flow in the human kidney using intra-arterial injection of ${ }^{133}$ Xenon. Relationship to function in normal and transplanted kidney. Clin. Sci., 34, 287-302.

SAPIRSTEIN, L.A., VIDT, D.G., MANDEL, M.J. \& HANHSEK, G. (1955). Volumes of distribution and clearances of intravenously injected creatinine. Am. J. Physiol., 181, 330-336. 
SCHALEKAMP, M.A.D.H., BIRKENHAGER, W.H., ZAAL, G.A. \& KOLSTERS, G. (1977). Haemodynamic characteristics of low renin hypertension. Clin. Sci. mol. Med., 52, 402-412.

SCHWARTZ, F.D. \& MADEZOFF, M.S.(1961). Simultaneous renal clearances of radiohippuran and PAH in man. Clin. Res., 9, 208.

SHILLINGFORD, J., BRUCE, J. \& GABE, I. (1967). Measurement of segmental venous flow by indicator dilution method. Br. Heart J., 24, 157-165.

SLOTKOFF, L.M., LOGAN, A., JOSE, P., D'AVELLA, J. \& EISNER, G.M. (1971). Microsphere measurement of intrarenal circulation of the dog. Circulation Res., 28 , $158-166$.

SMITH, H.W. (1940). Physiology of the renal circulation. Harvey Lect., 35, 204.

SMITH, H.W., FINKELSTEIN, N., ALIMINOSA, L., CRANFORD, B. \& GRABER, M.(1945). Renal clearances of substituted hippuric acid derivatives and other aromatic acids in dog and man. J. clin. Invest., 24, 388-404.

SMITH, H.W. (1956). Principles of renal physiology. Oxford University Press.

TAUXE, W.N., MAHER, F.T. \& TAYLOR, W.F. (1971). Effective renal plasma flow: estimation from theoretical volumes of distribution of intravenously injected ${ }^{131} \mathbf{I}$ orthocodohippurated. Proc. Mayo clin., 46, 524-531.

THORBURN, G.D., KOPALD, H.H., HERD, J.A., HOLLENBERG, N.K., O'MARCHOE, C.C.C., \& BARGER, A.S. (1963). Intrarenal distribution of nutrient blood flow determined by $\mathrm{Kr}^{85}$ in unanaesthetised dog. Circulation Res., 13, 290-307.

VARGA, L., Kelemen, I. \& KOVACH, A. (1968). Paper chromatographic study of radioactive contaminants of ${ }^{131}$ I-hippuran. J. nucl. Med., 9, 604-607.

WAGONER, R.D., TAUXE, W.N., MAHER, F.T. \& HUNT, J.C. (1964). Measurement of effective renal plasma flow with sodium iodohippurate ${ }^{131} \mathrm{I}$. J. Am. med. Ass., 187, 811-813.

WILKINSON, S.P., BERNARDI, M., PEARCE, P.E., BRITTON, K.E., BROWN, N.J.G., POSTON, L., CLARKE, M., JENNER, R. \& WILLIAMS, R. (1978). Validation of transit renography for the determination of intra renal distribution of plasma flow: comparison with the microsphere method in the unanaesthetised rabbit and pig. Clin. Sci. mol. Med., 55, 277-283.

ZIERLER, K.L. (1965). Equations for measuring blood flow by external monitoring of radioisotopes. Circulation Res., 16, 319-321. 